\title{
Drowsiness Detection to Prevent Accidents
}

\author{
Sangameshwar, Dharani V, Anirudh Reddy M, Gotlluri Jaswanthi
}

\begin{abstract}
In the current era, $60 \%$ of the accidents occur due to drowsiness. Drowsiness mainly occurs during early morning and during night times. This kind of road accident can cause a lot of harm to other people and government roads and other properties. These accidents finally lead to high injuries and death. To prevent this kind of accident and to save the lives of people, a lot of research is still going on.There are many kinds of methods to prevent this. But, everyone can't afford it or adjust to the systems environment. Though there are many systems none is able to provide accurate action, speed, sound, and no failure. In this paper, we designed the system in such a way that drivers won't get distracted, it is affordable, easy to fit in car environment and accurate results. In our proposed system when drivers feel dizzy and when he/she closes their eyes a huge beep sound will be produced by using text speech. We do all this with the latest technology of image processing under iot. We use raspberry pi which helps in producing accurate results. A high range of IR cameras will be set up in front of the driver, to monitor drivers facial expression and to calculate the eye ration. As mentioned drowsiness occurs during dusk and dawn IR camera helps in monitoring the face during even at darkness. This system is highly affordable, easy to access, easy implementation and accurate results.
\end{abstract}

Keywords: This kind of road accident can cause a lot of harm to other people and government roads and other properties. These accidents finally lead to high injuries and death.

\section{INTRODUCTION}

L ots of people die everyday due to road accidents. There are various ways by which an accident can occur. It may be caused because of using social media during driving, loss of concentration, consuming alcohol, getting distracted by the fellow traveller or due to drowsiness. Nowadays people are always in a hurry, so they are unable to stay healthy and they get easily tired by which it leads to drowsiness. According to a survey $40 \%$ of the accidents occur due to drowsiness. Lots of deaths, injuries and damage to government property. Based on this kind of case, researchers are developing a lot of systems to reduce accidents caused by drowsiness.

Revised Manuscript Received on March 11, 2020.

* Correspondence Author

Sangameshwar*, CSE department, GITAM Bengaluru, Bengaluru, India. Email: Sangamesh.biradar@gitam.edu

Dharani V, CSE department, GITAM Bengaluru, Bengaluru, India. Email: dharaniad21@gmail.com

Anirudh, CSE department, GITAM Bengaluru, Bengaluru, India. Email:anirudhreddymulumudi@gmail.com

G Jaswanthi, CSE department, GITAM Bengaluru, Bengaluru, India. Email: jashwanthigotluri@gmail.com

(C) The Authors. Published by Blue Eyes Intelligence Engineering and Sciences Publication (BEIESP). This is an open access article under the CC BY-NC-ND license (http://creativecommons.org/licenses/by-nc-nd/4.0/)
The drowsiness causing accidents is very dangerous, to prevent accidents we need to monitor the drivers drowsiness. Driver facial expressions, emotions, closing of eyes everything can be monitored using image processing method. Image processing helps in calculating all the values required, to monitor drivers drowsiness. On the basis of issues, we have proposed a method in which is completely based on facial ratio calculations, because of which we will be able to note down drivers drowsiness. In monitoring we mainly focus on drivers yawning, eye closure, emotions and other activities related to drowsiness. Here in this method we completely use non-intrusive technique where a driver will have no physical attachment to any kind sensors or wires attached. This system is fully non intrusive, simple and accurate. The system which we designed continuously monitors the eye movements using IR camera and raspberry pi. To the accurate results the camera will be placed in front of the driver near the steering. The camera is connected to raspberry pi with the help of cabled wire, so that the camera can be placed at drivers requirements. Our face has a lot of facial landmarks. Once the landmarks are properly identified, the ratio can be determined by eye closure. If the eye closure ratio becomes standard, then a buzzer sound will be produced which awakens the driver.The entire system runs on IR camera raspberry pi and the monitoring of ratios. The IR camera enables you to recognize the face landmarks during night times as well.

\section{LITERATURE SURVEY}

[1]Kusuma Kumari B.M, has proposed a system in which the the sensors will be attached to the driver, when the driver suddenly closes his/her eyes, the vibrater attached to the driver awakens him/her by vibrating. Immediate email will be sent to nearby police stations, in case of any accident.[2]Md. Yousuf Hossain has proposed a system where the eye ratio is calculated and everything depends on driver eye closure. If the driver closes his/her eyes a buzzer will be produced.[3]A. Subbarao, has proposed a system where it is completely sensored and wired, an light sensor, alcoholic sensor, and accident sensor is put in. The eye ratio is calculated, it also determines whether the driver has drunk, in case taking care of this, an accident occurs, and an accident sensor alerts the nearby police stations.[4]Nawal Alioua has proposed a system, when compared to other systems. This system deals with mouth yawning using Support Vector Machine (SVM) face detector,based on Circular Hough Transform (CHT). by this a buzzer sound will alert the driver.[5]According to the Rukhsar Khan system , an application will be installed in drivers mobile, which tells driver's activities and location and it also produces buzzer sound based eye ratio calculated.[6]A system developed by Arun sahayadas deals with robust system and sensor activity. It predicts accidents and also an alert message will be sent to drivers mobile.

Published By:

Blue Eyes Intelligence Engineering

\& Sciences Publication

DOI: 10.35940/ijeat.D6674.049420

Journal Website: www.ijeat.org

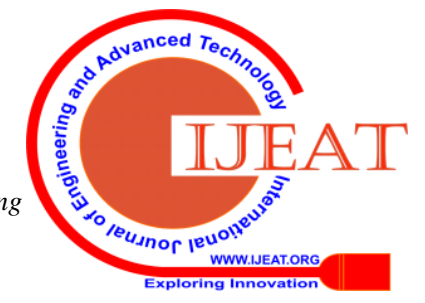


[7]In the system proposed by Garima Turan, he has similarity with Nawal alioua. It is based on mouth yawning and messages will be sent immediately in case an accident occurs.[8]Muhamad Ramzan has proposed a system in which the driver eye closure movements in addition mouth yawning ratio is also calculated. This type method takes a long procedure. Drowsiness should be taken immediately.[9]According to Md. Yousuf Hossain a proposed system the eye ratio is calculated and camera will be fixed in front of the driver using raspberry pi, this system may produce good speed of action.[10]Kalathiripi Rambabu designed a system in such a way that it only deals will captured images and light. If the captured images and drivers present face expressions matches an alert message will be sent , and doesn't save drivers' lives.

It is necessary to produce accurate results and speed of action, and a good loud sound to alert the driver as immediately as possible. Even a small delay also leads to major accidents. System should always be non-intrusive.

\section{PROPOSED SYSTEM}

The proposed system detects the facial landmarks of the driver. The pi camera will be set up in front of the driver. It monitors and measures drivers every expression and eye closure ratio. The raspberry pi attached to the camera calculates everything. When the driver closes his/her eyes due to drowsiness by a text speech buzzer, the driver's name will be produced loudly so that the driver gets alerted. In this system we use an IR camera which helps in monitoring the driver even during darkness. Image processing is a key technology by IOT. the system is completely non -intrusive, where no sensors, wired or physical connection is needed with the system.

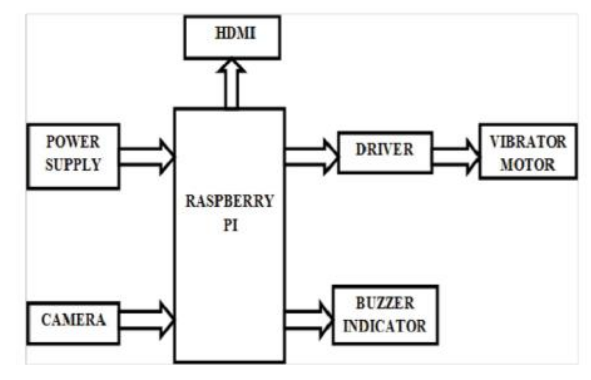

Fig 1: Architecture of Proposed System

In the above Fig 1 the components are explained below

\section{A.Camera (IR)}

IR camera is a special camera, which is designed in such a way that it can monitor the driver even during day and night times. Usually drowsiness occurs during night times, this IR camera is perfect for those kinds of situations. It helps proper calculation and it is connected to raspberry pi.

The camera is set in front of the driver. With the help of image processing the system becomes completely non-intrusive.

\section{B.Power supply}

To analyze the system and to see system results and run the system we need power supply. Power supply is must to run all the components set in the system.

\section{C.Raspberry pi}

This is the main heart of the system. It continuously monitors the facial landmarks of the driver with the help of image processing method. It calculates the eye closure ratio and sends a message to the buzzer. If the ratio meets above the normal, a high buzzer will be produced. It holds the entire code in it and runs accordingly.

\section{D.Vibration Motor}

It helps in getting signal from the pi and produces the beep sound immediately. This all takes place in nanoseconds

\section{DATA FLOW DIAGRAM}

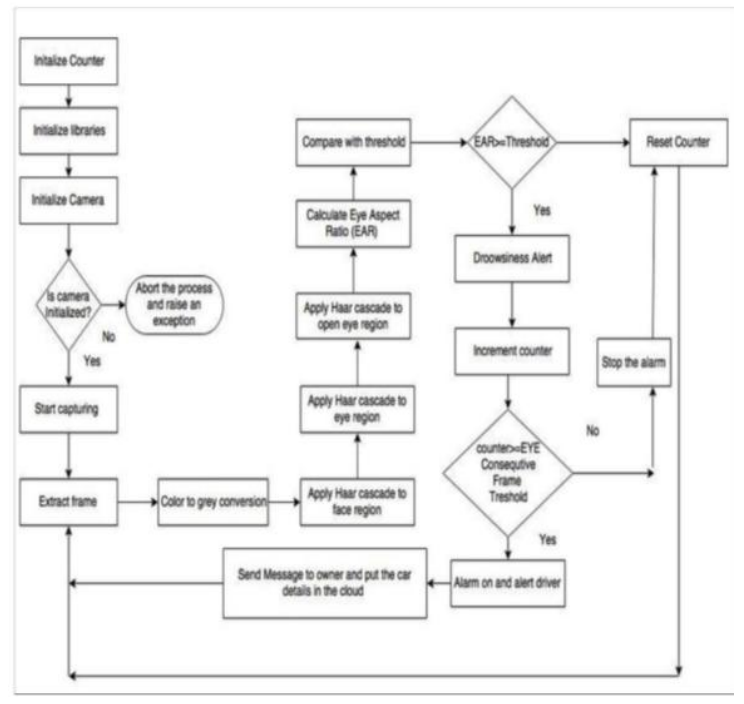

Fig 2: Flow chart

In the above data flow diagram the camera is initialized,using the Haar cascade method, EAR ratio will be calculated continuously. When the ratio is equal to zero a signal will be sent to the buzzer and a huge sound will be produced. This is a completely non-intrusive method. When the driver awakens from the drowsiness the alarm stops and the buzzer stops. By this process accidents will be reduced highly.this system is accurate in nature.

\section{RESULTS}

Since, we are using the IR camera even during the night time the system gives accurate results and gives beep sound in the least possible time. This can be easily implemented in real time and afforded by everyone at low cost. The device can be used by anyone without any training.

\section{CONCLUSION}

Everyday databases $40 \%$ of the accidents occur due to drowsiness. The reasons for drowsiness is lack of sleep and being healthy. Due to drowsiness accidents occur in huge ratios and this leads to high injury,death and damages. Through this system accidents can be prevented, it is completely environment and driver friendly. It is affordable, simple to implement, gives accurate results and finally saves drivers life.this system also monitors during night times and text speech sound helps the driver to wake up quickly.Hence,

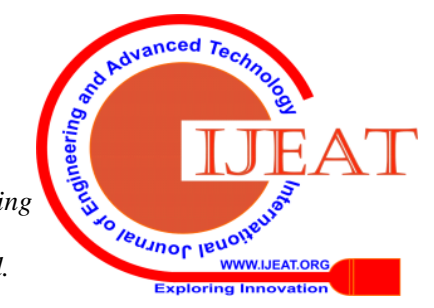


this system helps in saving life, can be used in army, government vehicles, helps in reducing damage to the government property like road, electric poles and nature as well.

\section{REFERENCES}

1. Kusuma Kumari B.M, Sampada Sethi, Ramakanth Kumar , Nishant Kumar , Atulit Shankar,'Detection of Driver Drowsiness using Eye Blink Sensor “,IJET,2018

2. Md. Yousuf Hossain, Fabian Parsia George,"IOT based Real-time Drowsy Driving Detection System for the Prevention of Road Accidents "ICIIBMS 2018.

3. A. Subbarao, K.Sahithya,'Driver Drowsiness Detection System for Vehicle Safety "International Journal of Innovative Technology and Exploring Engineering (IJITEE) ISSN: 2278-3075, Volume-8, Issue6S4, April 2019.

4. Nawal Alioua,Aouatif Amine,Mohammed Rziza, Driss Aboutajdine"Driver's Fatigue and Drowsiness Detection to Reduce Traffic Accidents on Road".

5. Rukhsar Khan, Shruti Menon, Shivraj Patil, Suraj Anchan, Saritha L. R, "Human Drowsiness Detection System",IJEAT, April, 2019.

6. Arun Sahayadhas, Kenneth Sundaraj and Murugappan Murugappan,"Detecting Driver Drowsiness Based on Sensors",2012 Dec 7.

7. Garima Turan, Sheifali Gupta,'Road Accidents Prevention system using Driver's Drowsiness Detection”, IJARCET,November 2013.

8. Muhammad Ramzan, Hikmat Ullah Khan, Shahid Mahmood Awan, Amina Ismail,Mahwish Ilyas,"Art of Drowsiness Detection", IEEE,Volume: 7.

9. Md. Yousuf Hossain ; Fabian Parsia George,'IOT Based Real-Time Drowsy Driving Detection System for the Prevention of Road Accidents",IEEE,Oct 2018.

10. Kalathiripi Rambabu, Jennifer Shalini, Shaik Ayesha Anjum, P.Ramya Ramani,"'Iot Based Drowsiness Detection System Using Labview “,IJRTE,2019.

\section{AUTHOR'S PROFILE}

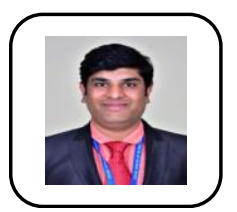

Sangameshwar, obtained his Bachelors degree in Computer Science and Engineering from VTU Belagavi. Then he obtained his masters in Digital Communication and Networking from Dayananda sagar college Engineering, bengaluru.He is pursuing his $\mathrm{PhD}$ in IOT and Edge Computing from GITAM, Bengaluru. Currently,he is working as an Assistant Professor in Department of Computer Science and technology, GITAM Deemed to be University, Bengaluru.He has working experience of 8 years and 9 months. He has huge passion towards new technologies like IOT, AI, ML, Phython, Cyber security and lot more. But, his favorite technology remain IOT and Edge computing. He has done various certifications with respect to technologies. He activity participates in every technical events. He has won 2nd prize in cyber security curate conducted by Nasscom. He has stood as a backbone for various projects.

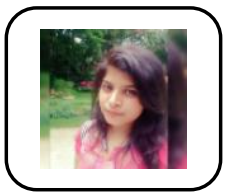

Dharani V, pursuing B.tech Final Year at GITAM, Bengaluru. He has certified by Automation Anywhere in RPA and DELL EMC for her course completion in Big Data Analytics. Her areas of intrest are Data Analysis, IOT, Machine Learning and Cyber Security. During her course time she completed many projects,few of them are Bots with respect to RPA, Smart Gardening System and Drowsiness Detection. She completed her schooling in Jain Global School and Higher education in Vidya Jyothi PU college, kolar.

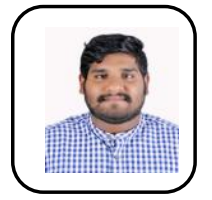

Anirudh Reddy, Mulumudi studying Computer Science Engineering 4th year. His interests are Machine learning, Python. He has Completed his intership at Azure skynet solutions. He has worked on data analytics and Machine learning projects such as chat bot, Play money Ball, etc. He has done few projects on Machine learning such as Image hashing, Human activity detection, etc, which are uploaded to my GitHub page (Anirudh1225). Hobbies are playing cricket, listening to music.

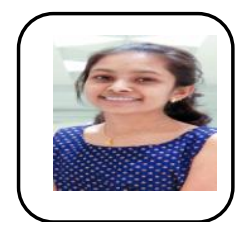

Gotluri Jaswanthi is pursuing B.tech Final year at GITAM, Bengaluru. She completed her schooling in Golden Valley and Higher education in Sri chaitanya Junior College, Tirupathi. Her areas of interest are Big Data, DBMS, Web Technology. She has done projects Dowsiness Detection. 